\title{
Pictorial and Verbal Discourse in W. G. Sebald's The Emigrants
}

\author{
Silke Horstkotte
}

W. G. Sebald, whose death in November 2001 shocked the literary public, has been hailed as one of the most innovative German language writers of recent years. Sebald lived in England but continued writing in German and has been established as a major figure of the literary scene both in Great Britain and North America through highly accomplished translations of his work. In Germany, critics have praised his idiosyncratic depiction of history, memory, and transgenerational transmission. The most innovative aspect of Sebald's works, however, is their highly original use of photographs. The majority of Sebald's texts include graphic reproductions of photographs, and photographs as visual and material objects also play an important role as plot elements. Among the central issues of Sebald's works is the role of photography in constructing personal, familial, and collective historical narratives, as well as the relation between (pictorial) memory and (verbal) narrative. Thus, Sebald's books lend themselves to an interdisciplinary approach that seeks to elucidate the relation between verbal and pictorial discourse in contemporary culture, and between verbal and pictorial media in the construction of history and memory.

During the course of the twentieth century, photographic, film, and televisual images have played an increasingly important role in the construction and documentation of historic events. The advent of the mass media has lead to a prolifera-

Silke Horstkotte received a Ph.D. from the University of Leipzig. Her research interests include 18 th century literature, German romanticism, narratology, and the 20th century novel. She is currently writing a book about narrated photographs in German novels after 1945. She can be reached at shorstkotte@yahoo.com. 
tion of images in non-imaginative communication. But images also play a central part in how imaginative discourses conceptualize history. W. J. T. Mitchell has coined the term "pictorial turn" for this increasing "imageness" in contemporary communication, taking up Richard Rorty's argument that the history of philosophy has progressed through a series of paradigm changes, or "turns": "The picture of ancient or medieval philosophy as concerned with things, the philosophy of the seventeenth through the nineteenth century as concerned with ideas, and the enlightened contemporary philosophical scene with words has considerable plausibility" (263). Rorty calls the last of these paradigm shifts the "linguistic turn"-a term that has found wide acceptance among literary critics. However, art historians like Mitchell and Gottfried Boehm have pointed out that by the end of the twentieth century, the "linguistic turn" has been replaced by another dominant paradigm: the "pictorial" (Mitchell) or "iconic" (Boehm) turn. Pictures, Mitchell argues, have a status "somewhere between . . . a 'paradigm' and an 'anomaly" in contemporary discourse, "emerging as a central topic of discussion in the human sciences in the way that language did: that is, as a kind of model or figure for other things (including figuration itself), and as an unsolved problem" (13). Thus, images are not only the paradigm in which contemporary culture must define its unresolved issues, but they are also the medium in which these issues are represented.

I wish to explore how literary texts respond to this paradigm shift, and how the increasing presence of images alters the meaning production of literary texts through a theoretically influenced reading of Sebald's The Emigrants. This collection of "four long stories" (subtitle) revolves around tales of emigration, exile, and homelessness. The four protagonists, whose names form the story headings, are personally known to the first-person narrator; their life stories, which make up the bulk of the narrative, are relayed to the narrator partly by themselves, partly by relatives, and partly by acquaintances. The highly credible form of oral life narrative receives further authentication through the presence of photographic and written material, which is (at least partly) reproduced in the book. The narrator, and thus the reader, is shown family albums and postcards sent by the protagonists, as well as given access to the protagonists' diaries and quotes from them.

Because Sebald consciously combines verbal and pictorial discourse, his texts raise questions about the function of images in contemporary culture. One aspect that needs to be addressed when discussing the relative functions of photography and text in The Emigrants concerns the suggestion of authenticity: because the camera captures and preserves the reflection of light at a certain time, in a certain place, photographs are often conceived of as "direct" material traces of the photographed people and objects. In Roland Barthes's words, "The photograph is literally an emanation of the referent . . . light, though impalpable, is here a carnal medium, a skin I share with anyone who has been photographed" (Camera Lucida 80-81). In semiotic terms, Barthes would be said to argue for the indexical nature of photographs. According to Charles Sanders Peirce's definition, there are three kinds of signs: conic signs, which stand in a relation of similarity to their referent; indexical signs, which have a relation of cause and effect; and symbolic signs, which stand in a purely conventional, arbitrary relation to their referents. A (non- 
abstract) painting, for example, is an iconic sign because it resembles that which it depicts; a footprint is an indexical sign because it has been produced by a foot (although it is also iconic, since it closely resembles the shape of the foot); and linguistic signs are symbolic because words stand in an arbitrary, conventional relation to their referents.

As Ernst van Alphen has pointed out, photographs are both iconic and indexical signs: "Photographs are perfect icons because of the high similarity between the image and the object being referred to; but they are often seen as the exemplary index as well because of the existential relation of touch between the light the object reflects or emits and the sensitive layer of film on which the light fell" (133). One of the problems with photographs is that the two kinds of reference are often confused. However, iconicity is not an indicator of indexicality; on the contrary, I propose that it is frequently the opposite. The iconicity of photographs is highlighted by critics who question the distinction between the documentary and the aesthetic, stressing the imaginative tendencies inherent in all pictorial discourse. Christina von Braun, for example, argues that because the photograph inserts itself like a protective barrier between us and the real, its powers of representation are diminished. Instead, von Braun continues, the photograph is reduced to transforming horror into the aesthetic, thus becoming what she terms a "photo morgana" (116). Indeed, I would agree that the authenticity suggested by the indexical reference of photographs is deceptive. It is well known that photographs can be manipulated, and not just since the introduction of digital photography. A retouched photo features in the final story of The Emigrants: the photo supposedly showing the Nazi burning of books in Würzburg must be manipulated because the book burning took place at night, when it was too dark to take photos (274). Photos can "lie" (Jaubert) in different ways; they can be touched up, i.e. visually altered, but they can also be wrongly contextualized, since the interpretation of photos depends on narrative frames. Because of their association with discourses of history and memory, however, the photos in The Emigrants are more then mere "photo morganas." They retain the visual power to expose and therefore transcend arbitrary distinctions between documentary and imaginative discourse.

Photographs can also have symbolic properties because a single, isolated photograph can hint at a larger context with which it stands in a conventional relation. For instance, a black-and-white photograph of a bombed city is conventionally taken to refer to the second World War and the allied bombing of Germany. Photographs of the selection ramp at Auschwitz, frequently reproduced in history books, are symbolic of the Holocaust as a whole. Because of this symbolic property, photographs share certain aspects with linguistic signs, which are also symbolic. Recent theories of photography have highlighted the constructedness of images within language. Because "the interpretation of images is, for the most part, conducted in various forms of verbal discourse" (Mitchell 209), photography is often understood to be absorbed by language in actual usage. After all, Marianne Hirsch argues, "[p]hotographs are fragments of stories, never stories in themselves" (83). This is obvious in the case of family photographs-Hirsch's object of study - where narrative frames take concrete shape through such verbal additions 
as the captions in family albums. The family album itself functions as a narrative frame since it is defined by conventionalized assumptions: that the photographs depict one and the same family, that of the album owner; that they are arranged chronologically; and that they represent the major stages in that family's life. In fact, family photographs acquire meaning only if and when they are placed within narrative frames; an isolated family photograph, showing people unknown to the viewer, does not have any meaning. Hirsch illustrates this with an anecdote from her own family: her cousin, whose parents have died young, has inherited many unknown family pictures. Since she cannot identify the photographed relatives, the photos mean nothing to her. In fact, Hirsch's cousin has let her husband throw them away. For Hirsch, however, these photos would have had a special meaning since she would have been able to identify the women in the pictures as her grandmother and aunt. Hirsch concludes: "[I] mages that to my cousin were anonymous, meaningless, and even funny, because she could not identify them, to me would have been integral pieces of a life story, full of meaning and resonance" (xii).

Narrative frames, although they usually remain unspoken, are frequently thought of as verbal in nature. Some theorists of photography have gone on to argue that every photograph is linguistically framed. This view is articulated by Victor Burgin when he states that "even the uncaptioned 'art' photograph is invaded by language in the very moment it is looked at: in memory, in association, snatches of words and images continually intermingle and exchange one for the other" (51). Photography, Burgin concludes, is not a purely visual medium but "a complex of exchanges between the verbal and the visual" (58). Because photographs "depend on ... a narrative act of adoption that transforms rectangular pieces of cardboard into telling details connecting lives and stories across continents and generations" (Hirsch xii), their reception mirrors that of texts; hence, the reception process of photographs is often called "reading."

In The Emigrants, the graphically reproduced photographs are framed by the surrounding verbal narrative in ways that are typical of the usage of family photographs. The photos are placed in narratives of familial history and memory: frequently, the text directly below them is printed in a manner that imitates the captions in family albums. Sometimes, the narrator actually reproduces the captions he has read in albums (83). However, this can be deceptive: although the line "Die Theres, der Kasimir und ich" is printed like a caption (108), no mention is made of the photograph in the narrative. Thus, the reader is led to assume that this is a photograph of the speaker (the narrator's aunt Fini) and her two siblings simply because of the way the text is arranged around the photograph. Since there is no indication in the text that this is the case, the photograph can be seen to influence the narrative frame just as much as the narrative frame shapes the meaning of the photograph. Thus, the photograph does not only add to the text, it alters the textual meaning. This is generally true of photography: family photographs are not inserted into ready-made narrative frames, they produce and shape these frames. In fact, as Hirsch has pointed out, by the second half of the twentieth century the narrative of familial history has become an effect of photographic practices: "The family photo both displays the cohesion of the family and is an instrument of its 
togetherness; it both chronicles family rituals and constitutes a prime objective of those rituals" (7).

Thus, we need to consider textual narrative and the visual media as complementary rather than conflicting aspects within intermedial texts, taking up Mieke Bal's suggestion "to make discourse a partner, rather than dominant opponent, of visuality" (Reading "Rembrandt" 288). I do not agree with the view that verbality is a dominant medium that somehow "absorbs" visuality; rather, I would like to propose that both verbal and visual media are ambivalent: while visual media have narrative aspects, narrative in its own turn has visual aspects because it causes the reader to visualize scenes. Mitchell has offered a reception-oriented description of the visuality inherent in verbal narrative by pointing out that "although images and pictures can only be conjured up 'figuratively' in verbal discourse," this "does not mean that the conjuring fails to occur or that the reader/listener 'sees' nothing" (96). Thus, Mitchell argues that "the visual representations appropriate to a discourse need not be imported: they are already immanent in the words, in the fabric of description, narrative 'vision,' represented objects and places, metaphors, formal arrangements, and distinctions of textual functions" (99).

Bal's "quotation" is a useful concept for understanding how the reproduction of photographs adds to the meaning of The Emigrants. Bal situates quotation "at the intersection of iconography and intertextuality," emphasizing "the active participation of visual images in cultural dialogue" (Quoting Caravaggio 8-9). Thus, the term "quotation" conceptually combines intertextual and pictorial strategies, suggesting that images have the same source value in imaginative discourse as texts. Such intermedial quotations serve three functions within imaginative discourse. First, the "literal" quotation of words or images authenticates the surrounding fiction. Second, since quotations are regarded as fragments of reality, they become the "product of a manipulation." Third, quotation serves a mimetic impulse (10). All three functions can be seen at work in The Emigrants. Because the photographs in The Emigrants are framed within imaginative narrative, they cannot function as a marker of reality. Their indexicality is diminished since their referents are part of imaginative discourse, hence not real. What the photos do instead is performatively suggest reality and authenticity to the reader. This reality invoked by the showing of photographs is a literary, and therefore constructed, reality: not "real" reality at all, but a reality effect which is not mimetic, but poietic, and therefore the exact opposite of realism (The Rustle of Language). In van Alphen's words, the photographs in The Emigrants do not constitute "facts," they adopt a "rhetoric of fact" which "does not claim that what it represents was real; rather, it creates a sense that what it represents was real" (21). The constructed nature of this rhetoric needs to be kept in mind when trying to understand the function of photography within imaginative discourse.

One obvious marker of the rhetoricity of fact lies in the arrangement of narrative and photography in The Emigrants, which is based on aesthetic principles. The spatial arrangement of photographs within The Emigrants is therefore predicated upon the second function of intermedial quotation: manipulation. The aesthetic quality of this arrangement is foregrounded by the way the very first photo- 
graph in The Emigrants is placed within the narrative. It is set after the title of the first story, "Dr. Henry Selwyn," but before the first sentence of the verbal narrative. The photo shows a huge oak tree with wide branches spreading out over what appears to be an old neglected cemetery. The tombstones look weathered, some are leaning over. The lawn between the graves is untended, there are no flowers anywhere. There is no mention of such a cemetery in the story. But because the cemetery in the photograph is old and untended, and because it is somewhat reminiscent of Jewish cemeteries in Eastern Europe, it could be taken for a Jewish cemetery. The story, after all, has a Jewish protagonist. The photograph can therefore be interpreted as symbolic of the condition of Jews in post-Holocaust Europe. This seems fitting because there are many other indirect references to the Holocaust in The Emigrants. On the other hand, two of the grave markers in the background of the photograph, right by the horizon, seem to be crosses, which suggests a Christian cemetery. But maybe that is just another part of the cemetery-we cannot know. Thus, before the reader has read even one sentence of the story, she is already faced with expectations of what the story will be about: death, forgetting, loneliness, and perhaps the Holocaust. At the same time, it has become obvious that these expectations, which take the structure of narrative frames (not to be confused with the actual verbal narrative), are based on the reader's associations. The reality effect of photography therefore has a strongly performative quality that needs to be addressed within a reception-oriented approach.

Before I discuss the special relation of photography and death, which is important, let me explain how the photograph interacts with the text of the story, because it is this interaction that distinguishes the photographs in The Emigrants from real, material photos. When I talk about "interaction" here, I mean to indicate a process that happens at the reception stage, but that is also based on certain objective factors, of which the spatial organization of photography and text is the principal one. Between the title "Dr. Henry Selwyn" and the graveyard photograph there are two lines of text, right at the bottom of the title page of the story, printed like two lines of a poem or a distich (although the syllable count does not match): "Zerstöret das Letzte / die Erinnerung nicht" (5). This two-liner is difficult to translate into English because the English language does not allow the splitting up of a verb and its negation, which requires the reader to read through the whole statement before she realizes that the two lines are not an exhortation to destroy, but NOT to destroy memory. Another problem is that in English, it is not possible to substantiate "last" so as to avoid using a noun that would clarify what kind of last thing memory is. The motto (for that appears to be the function of these two lines) sounds as familiar as a well-known quotation, but I have not been able to verify its source. It might be something by Hannah Arendt, but most likely it is just a paraphrase of one of the most familiar notions in the German debate on memory, remembrance, and the Holocaust: the need to remember, because memory is all that is left. Because of the use of the imperative, the motto appears to directly address the reader; it can therefore be read as an instruction for the reception of the whole collection.

The other stories are preceded by similar quotes, two of which have verifiable sources. The motto introducing the second story, "Paul Bereyter," is a quotation 
from Jean Paul's "Vorschule der Ästhetik," a compendium of classicist aesthetics and poetics. Jean Paul writes about the hermetic German philosopher, Hamann: "Thus, the great Hamann is a deep sky full of telescopic stars, and some nebulae cannot be pierced by the eye" (14). As a motto in The Emigrants, this has been shortened to "Manche Nebelflecken / löset kein Auge auf" (39). Jean Paul's quotation, which is part of an argument about the incomprehensibility of philosophical discourse, and in prose, is here made to look like a two-liner from a poem. Read within the context of The Emigrants, it may be interpreted as an epistemological argument about the general impossibility of knowing the Other. The German "Nebelflecken" has a double meaning: it refers to an astronomical phenomenon, the nebula, as well as to a condition of the eye, known as clouding. In the source, the context is clearly astronomical. In The Emigrants, however, this context has been elided, making the reference ambiguous. In fact, since the motto mentions looking and the eye, it will probably be taken to refer to the eye condition of clouding. This uncanny sense of an eye looking at an eye is not present in Jean Paul.

The third story, "Ambros Adelwarth," is again preceded by a motto, this time in English: "My field of corn is / but a crop of tears" (95). When looked up in Bartlett's Familiar Quotations, this turns out to be an inaccurate quotation from "Tichborne's Elegy," a work by the little-known British poet Chidiock Tichborne (1558-1586). The original quote reads:

My prime of youth is but a frost of cares,

My feast of joy is but a dish of pain,

My crop of corn is but a field of tares,

And all my good is but vain hope of gain:

The day is past, and yet I saw no sun,

And now I live, and now my life is done. (611, emphasis added)

The way it is stated in "Tichborne's Elegy," the line is somewhat arcane: what exactly is a "field of tares"? Tares, or bearded darnel, are an oriental plant mentioned in the parable of the tares among the wheat in Matthew 13: 25-30. As Easton's Illustrated Bible Dictionary explains, "It is the Lolium temulentum, a species of rye-grass, the seeds of which are a strong soporific poison. It bears the closest resemblance to wheat till the ear appears, and only then the difference is discovered. It grows plentifully in Syria and Palestine" (654). Tichborne thus identifies the crop of corn, promising wealth and nourishment, with a field of obscure, poisonous plants. In the same manner, each of the poem's lines combines two paradoxical statements. The speaker is in the prime of his youth, yet at the same time he has the "frost of cares" emblematic of old age; a "feast of joy" is simultaneously "a dish of pain," and so on. Sebald, however, exchanges the nouns "crop" and "field," and thereby turns a paradoxical statement into a logical one about the nature of time, which will destroy everything so that the "field of corn," with its promise of a rich crop, in fact only leads to a "crop of tears." In "Tichborne's Elegy," it is not possible to interpret the line chronologically because the crop is mentioned before the field. Sebald has also exchanged the noun "tares," with its 
arcane biblical reference, for the more conventionally poetic "tears."

The motto of the fourth story is not verifiable, although it sounds familiar enough: "They come at dusk / and seek life" (217). This quote resembles various gothic poems about vampirism, and can thus be connected with the motif of the living dead, which plays an important role in The Emigrants. Two techniques are characteristic of Sebald's use of mottoes: invention and recontextualization. The mottoes are made to look like quotes: because that is the conventional expectation of mottoes, but also because they are printed like bits of poetry. They have the appearance of something that can be authenticated. But on closer examination, two of the four mottoes turn out to have no textual basis (even if they did, this would not significantly change my argument). Hence, their authenticity is manufactured. The other two mottoes are indeed quotations, but they are taken out of context so as to alter their meaning, and in one case even the actual words are changed. The mottoes are also influenced through their combination with the following narrative, which replaces their original frame of reference and adds new layers of meaning to the mottoes.

Like the mottoes, the photographs reproduced in The Emigrants are informed by the narrative context. I have already discussed the first photograph-the cemetery. It is placed before the first sentence of the narrative, on the first page of the story, which is preceded by the page with the title and motto. By placing the title, motto, photograph, and narrative in this order, Sebald reproduces a conventional aesthetic structure: that of the baroque emblem with its combination of motto, picture, and subscription. Thus, the distribution of text and image conveys a special meaning to the cemetery photo: if it is viewed as part of a tripartite emblematic structure, the photo functions as an illustration of the motto that will be further explicated in the subscription. The function of pictures within emblematic structures is pedagogic. The picture illustrates the motto in a memorable manner; the reader of emblem books is meant to memorize the pictures as a way to internalizing the expressed moral values. Emblematic pictures are symbolic signs because their reference is conventionalized and arbitrary. The cemetery photo is quite obviously not iconic (there is no cemetery in the story), but symbolic. Following the exhortation to remember, the photo symbolizes that which the reader is asked to remember: the dead. And indeed the following narrative tells of a dead friend whose body turns up again under unexpected circumstances. The protagonist of the story, Dr. Henry Selwyn, has told the first-person narrator about this friend, the Swiss mountain guide Johannes Naegeli, who disappeared in the Swiss Alps in 1914. In 1986, the narrator stumbles across a Swiss newspaper carrying a notice that the remains of Johannes Naegeli's body have been discovered inside the Oberaar glacier. "So this is how they return, the dead," the narrator muses (36).

Thus, the introductory photograph can be read as part of the narrative, using the technique known as the "hermeneutic circle." This circle consists of two steps, which are then repeated. In a first step, the details of a narrative determine the reader's expectation of what the whole narrative will be like; in a second step, the reader then adapts his understanding of the details to his interpretation of the whole. This process is set into motion within the emblematic structure of "Dr. 
Henry Selwyn." The motto, with its exhortation to remember, raises the expectation that the story will be about memory. The graveyard photograph then suggests that it is the dead, already half-forgotten since nobody is tending their graves, who are in need of remembrance. This interpretation gains high plausibility through the ensuing plot, which forms the subscription or third part of the emblem and which reconfirms the interpretation of the photo as showing that which needs to be remembered. At the same time, the subscription offers several concrete examples of deceased people in need of remembrance. There is Johannes Naegeli, who is still present in the tales of his friend Henry Selwyn. There is Dr. Selwyn himself, whom the narrator is presenting to the readers. Most of all, it is the half-forgotten world of pre-Holocaust Jewish life that is kept alive in the life story of Dr. Henry Selwyn, the former Hersch Seweryn, and in the other The Emigrants stories-especially in the diary of Luisa Lanzberg included in the fourth story.

Photography is particularly suited to preserving the memory of the dead because of its function as index, trace, or fetish. While Barthes insists that "the photograph does not call up the past" (Camera Lucida 82), and Marguerite Duras has gone even further in claiming that "photographs promote forgetting .... It's a confirmation of death" (89), Hirsch has convincingly argued for photography's unique ability to bring the past back to life: "Photography's relation to loss and death is not to mediate the process of individual and collective memory but to bring the past back in the form of a ghostly revenant, emphasizing, at the same time, its immutable and irreversible pastness and irretrievability" (20). This ambiguity is characteristic of the photos in The Emigrants. The graveyard photo introducing the first story creates a strong sense of presence, while at the same time putting that which is presented at a distance. The dead are both irrevocably dead and past, and uncannily present, in the cemetery. This sense of an absent presence, or a presented absence, is quite strong in the numerous photographic portraits in The Emigrants. In the "Paul Bereyter" story, Madame Landau refers to this when she remarks that "looking at the pictures in [Paul Bereyter's family album], it has actually seemed to me-and it still seems that way — as if the dead were returning or as if we ourselves were about to go to them" (69). The sense of presence is not solely a property of the photographs, since it is deliberately evoked by the narrative frame. The interplay of verbal and pictorial discourse here artfully guides the reader's reactions by pointing her towards certain frames of reference.

At the same time, there are strong indications that the photographs are not to be mistaken for authentic documents. One clue lies in the way verbal sources are altered and forged throughout the stories. I have already discussed the manipulation of original quotations in the mottoes. The same irreverence towards sources is characteristic of the narrator's use of written documents. In the second story, the narrator is given a set of exercise books belonging to Paul Bereyter which, the narrator claims, contain excerpts from Bereyter's favorite authors: Altenberg, Trakl, Wittgenstein, and others (86). Into this passage, the author has inserted photographs or photocopies of two pages of handwritten notes on ruled paper. However, these notes do not contain any reference to the mentioned authors. Instead, they describe two relatives, Aunt Olga and Aunt Lula. If the reader wants to make sense 
of this contradiction, she is faced with two possible solutions. First, she might assume that the narrator is highly unreliable, since his description of the exercise books is not supported by the reproduced material. Second, she could also conclude that the reprinted pages are not taken from the exercise books the narrator describes. In this case, the author would be purposefully misleading the reader by presenting her with false visual clues. Since the narrator, however, is not a real person but a function of the text, we must assume that Sebald means to deliberately mislead the reader.

This also draws the reliability of photographic evidence into doubt. Again, there are clues in the text pointing at this unreliability. The most obvious of these concerns the case of the disappeared and rediscovered mountain guide Johannes Naegeli. To prove the authenticity of this story, the author has reproduced the newspaper cutting containing the item about Naegeli's rediscovered body. But instead of substantiating this claim to authenticity, the reproduction refutes it. The narrator has relayed how he discovered the news item, by chance, in a paper which he had bought in Zürich. A close look at the reproduction, however, reveals that the newspaper in this photo is taken from an archive. The top of the paper bears a date stamp of the kind used for archival purposes, and directly below the top line someone has scrawled the following filing information: "CH/FD/Morts suspectes" (37). Thus, the newspaper cannot have been bought by chance: it has been searched for in an archive. Again, the gesture of showing that motivates the reproduction of the newspaper page involves the three contradictory functions of intermedial quotation: authentication, manipulation, and mimetic impulse.

Since the reproduced images in The Emigrants contain information separate from that conveyed by the verbal narrative, can they be understood to have narrative properties in and by themselves? Some critics would say yes, although this is deeply contested territory and most literary critics would like to restrict narrativity to verbal discourse. Bal, however, has persuasively argued for the narrative dimension of images, which she situates on the level of reception or "the way the story of reading the images happens" (Double Exposures 222). Another argument in favor of the narrativity of images that Bal uses is the presence of point of view or focalizer (as it is now commonly called) in images. Because of their visuality, images-and photographs in particular-possess an element of perspective. Hence, they can be analyzed under narratological terms: "Narrative comprises the processing of a motivation. This motivation can be analyzed through the narratological question of the focalizer. This agent is the bearer of the vision which informs and colors the image in time" (222). Because the act of "reading" pictures occurs in time, and is colored by the focalizer's perspective, Bal argues that even "static images narrate" (222). I have already pointed out that photographs have narrative properties because of the performative aspect inherent in their presentation. This becomes even more obvious if we consider showing the photographs as a discursive act or gesture of the author/narrator. Thus, the semiology of photographs does not differ significantly from that of the printed text. However, the fictional and imaginative aspects of photography are masked in The Emigrants because of the historical and autobiographical content of the narrative. 
Our understanding of photographs is predicated on the trope of witness, which is central to the function of images in historiographic writing. As van Alphen has pointed out, "[rhetorically] the photograph operates at the same level as autobiography. It is a 'trope of witness,' it persuades the viewer of its testimonial and factual authority in ways that are unavailable to narrative" (22). This trope of witness inherent in photography is reinforced in The Emigrants through the use of autobiographical references within the verbal narrative. The narrator of The Emigrants (perhaps I should say the narrators) bears a close resemblance to the author. In "Dr. Henry Selwyn," we encounter the narrator as he is looking for an apartment in the vicinity of Norwich, England, where he has just accepted a position and where Sebald himself worked as a university lecturer. The narrator of the second story, "Paul Bereyter," informs us that he was born in a South German village which he abbreviates as "W" (45); readers aware of Sebald's biography will be tempted to identify this with Wertach, where the author spent his childhood years. A lot has been made of these autobiographical traces, and many reviewers have (naively) assumed that the four narrators in The Emigrants must be the same person and identified that person with the author. Some have even gone so far as to conclude that the protagonists' life stories must be "authentic" and that the characters are therefore "real people Sebald has met" (Detering 74). This touches upon a number of issues recent autobiographic theory has tried to come to terms with: Who or what is the subject of autobiography? Are the perspectives and experiences communicated true or created? Is autobiography an effort to define or recapture the self?

In "Conditions and Limits of Autobiography," often cited as a seminal text of autobiographic theory, French critic Georges Gusdorf defines autobiography as the reconstruction of the "unity of a life across time" (37), presupposing a self that is sure of himself (this self is invariably male) and an unproblematic relation between the writing and the reflected self. However, Gusdorf acknowledges that there is a moment of self-invention present in autobiography. "To create and in creating to be created," he insists, "ought to be the motto of autobiography" (44). This creation process is conceived of as a constructive process that is not distinct from the narrative process inherent in all self-creation. After all, we all need narrative to make sense of our world. As Bal states, "Narrative is one of the most pervasive modes of meaning production. By means of narrative, members of a given culture represent and convey happenings, ideas, arguments, experiences, imagined states of the world, and mythical theories of origin" ("Narrative and the Visual and Literary Arts" 328). Thus, narrative practice is essential to the construction of a self, even prior to literary presentations (Holstein and Gubrium 104). Jerome Bruner, among others, reminds us that any narration of a life story is going to proceed along the lines of some sort of narrative plot that guides the writer's selection process. This emplotment creates a sense of unity and coherence: "[A] utobiography wraps up the interrupted and fragmentary discourses of identity ... and presents them as persons themselves" (Gilmore 17). Autobiography is the result of a delicate negotiation between a historical and a textual self. According to this view, independently of whether the described events are "true" or not, autobiography has certain 
fictional aspects because of its constructive function.

The notion of constructivism has been radicalized by poststructuralist thinkers like Jacques Derrida and Paul de Man, who have argued that the self is no more than an effect of language, a textual construction, and that there is no "true" self prior to narrative presentations. This view is supported by recent findings in the neurosciences, which have concluded that experience and memory are mediated by narrative frames that are formulated in the present, yet guide our perception of the past: "[What] we recall is not what we actually experienced, but rather a reconstruction of what we experienced that is consistent with our current goals and our knowledge of the world" (Schacter and Scarry 19). Thus, constructions of identity are predicated not on an elusive past "truth" but upon the present needs of the subject: "Memory [is] not only literally essential to the constitution of identity, but also crucial in the sense that it is constantly revising and editing the remembered past to square with the needs and requirements of the self we have become in any present" (Schacter and Scarry 293). As van Alphen has pointed out, experience itself is already a representation of events, hence mediated and dependent upon narrative frames: "The notion of experience ... implies a certain distance from the event. Hence the experience of an event is already a representation; it is not the event itself" (44).

Leigh Gilmore calls the study of autobiography "autobiographics" in order to describe the elements of self-invention, self-discovery, and self-representation. In classical autobiographies, this self-invention remains hidden and unacknowledged. In postmodern autobiographical texts, however, the constructed aspects of autobiography can be highlighted. Another factor to take into account when interpreting autobiographic narratives is the close interplay of generic expectations on the one hand and the variety of postmodern autobiographical texts on the other hand. Paul John Eakin has concluded that "even the most superficial acquaintance with the diversity of works customarily received as autobiographies should lead us to recognize that "there is no intrinsically autobiographical form"” (20). Postmodern autobiographies that foreground the constructedness of the autobiographic self frequently cross the border between fiction and non-fiction. Recent autobiographic theories have coined a number of terms to account for the variety of forms in new autobiographical writing. While terms such as "ego-documents," "life-writing texts," and "testimony" stress the non-fictional aspects of autobiographic documents, postmodern autobiographies that include fictional elements have been called "nouvelle autobiographie," "autofiction," or "fictobiography."

The concept of fictobiography, with its conscious mixture of documentary and imaginative aspects, can be used as a generic description of The Emigrants. On the one hand, the The Emigrants stories contain autobiographic references; on the other hand, the arrangement of verbal and pictorial discourse is too contrived to be authentic. The frames of representation in The Emigrants are arranged according to aesthetic principles and form a spatial structure. The inclusion of textual sourcesthe journals of Paul Bereyter, Luisa Lanzberg, and Ambros Adelwarth-creates a chinese-box narrative structure. This is supported by the quotation of images, which also evokes a visual structuring. The narrative structure is thus highly 
aesthetic and inauthentic. And yet, there is a testimonial aspect to the narrative. This close interplay of imaginative and documentary aspects raises the question of reliability and credibility.

The unreliability of imaginative narrative is discussed in the story of Ambros Adelwarth. Uncle Ambros, the narrator is told by his Aunt Fini, may have suffered from a mental disease called "Korsakow's syndrome," where the loss of memory is compensated by the invention of highly incredible stories (149). Because the uncle had "an infallible memory," but no corresponding "ability to remember," Aunt Fini explains, his phantastic tales were for him "a torture and at the same time an attempt to free himself" (146). Aunt Fini distinguishes between two functions of memory: storage and retrieval. The uncle's "infallible memory" has faithfully stored his past experiences; however, he is not able to retrieve these memories in a manner that would endow them with a sense for the present. This has to do with the interplay of narrative and visual memory. The connection between visibility and memory has been the object of much recent research. Findings in the neurosciences suggest that individual memories are stored in the brain in the form of mental images (Pöppel). An individual will have, on average, a thousand of these images, which are static and without color; in photographic jargon, we would say they are black and white. Thus, images of memory share central properties with family photographs. It is therefore not surprising that photography is often used as a metaphor for memory.

While neuroscientific research stresses the visual nature of memory, I would like to argue that mental images need to be integrated with narrative frames in order to make sense to the subject. Memory as a whole therefore has a narrative structure, relying on conventional narrative frames. After all, language is still the dominant mode of our interaction with the world. Recent trends in psychotherapy stress that we are able to construct our own realities through language (Freedman and Combs); hence, we are able to "story" our existence (White and Epston). It is this narrative faculty that Uncle Ambros lacks. Because the uncle was unable to adequately frame his memories, Aunt Fini now takes recourse to a different kind of narrative frame: she shows the narrator the photographs in the family album. Like the family album, with its reliance on narrative frames, memory itself is structured like an imagetext, as Hirsch has suggested: "The spatiality of memory mapped onto its temporality, its visual combined with its verbal dimension, makes memory ... in itself an "imagetext"' (22).

I wish to suggest that the possibilities of different media to represent memory and history are foregrounded in Sebald's texts because these deal, directly and indirectly, with a traumatic historical experience that has been notoriously difficult to represent: the Holocaust. This may seem surprising since quantitatively, the Holocaust plays a comparatively small part in The Emigrants. It makes a brief appearance in the second story, "Paul Bereyter," where the protagonist is dismissed from his position as a schoolteacher because he is one-fourth Jewish according to the anti-Semitic Nuremberg race laws, and where a minor character, Paul's friend Helen Hollaender, is presumed to have been deported- " probably at first to Theresienstadt" (73). The Holocaust is largely absent from the first and third stories, although the central characters, Dr. Henry Selwyn and Cosmo Salomon, 
are Jewish emigrants. It is most apparent in the fourth story, "Max Aurach" ("Max Ferber" in the English translation). Aurach has survived the Holocaust in an English boarding school, but his parents have been killed in the death camps. Central to all four stories is the characters' preoccupation with remembrance and forgetting, and here the Holocaust does play a central role. In the second story, Madame Landau, Paul Bereyter's neighbor, reminds the narrator of "the thoroughness with which these people [the Germans] . . have withheld, concealed and, as it sometimes seems to me, actually forgotten everything" (74). In the fourth story, the narrator's attempt to visit the places of Aurach's mother's childhood is thwarted by the "spiritual impoverishedness and lack of memory of the Germans" (338).

Sebald also uses leitmotifs that indirectly hint at the Holocaust. Paul Bereyter's obsession with railway trains and schedules, for instance, is an oblique allusion to the Nazis' use of railway trains in deporting Jews to the death camps. For Bereyter, his neighbor tells the narrator, "the railway ... had a deeper meaning. It probably always seemed to him as if it was leading to death" (90). Like the first story, the one about Bereyter is introduced by an emblematic composition of motto, picture, and subscription. Here, the meaning of the photograph and its relation to the following narrative is much easier to comprehend than in "Dr. Henry Selwyn," while the relation of photograph to motto is more enigmatic. The photo shows a set of railway tracks running off into the middle distance of a deserted woody landscape. The first sentence of the subscription informs the reader that Bereyter committed suicide by throwing himself under a railway train "at the spot where the railway tracks curve out of the little willow copse into the open field" (41). This could well be a description of the railway tracks in the photograph. In fact, because the initial sentence is printed directly below the photograph, readers will probably take it that way. The relation between picture and subscription, then, seems simple enough. What about the motto, though? It is the Paul quote mentioned above: "Some nebulae / cannot be pierced by the eye." The idea expressed here, that the clouded part of the eye is inaccessible to vision, must be read metaphorically as a hint at our inability to comprehend the Other. If the photograph is read as an emblematic picture, it therefore acquires symbolic undertones which are linked with the question (unanswered in the narrative) of why Bereyter chose to commit suicide in such a way.

Railway tracks are one of the most pervasive symbols for the Holocaust. No film about the Holocaust, whether fictional or documentary, can do without images of railways or railway tracks. The Holocaust, difficult as it is to conceptualize, has become identified with a standard repertory of highly symbolic (hence arbitrary) images, the most powerful of which is the selection ramp at Auschwitz with its double set of railway tracks. In a volume about images of the Holocaust, Willi Goetschel has argued that images acquire meaning through the act of circulation, and that circulation has charged Holocaust pictures in particular with a symbolic meaning that far outreaches their visual content (134). Goetschel's assessment of this symbolic potential of images, which is also noticeable in the railway track photograph in The Emigrants, is critical. He sees the symbolic Holocaust picture as exemplary of the contradictory trends to place Holocaust representations under 
taboo and to try to come to terms with the Holocaust through the use of images which are necessarily reductive. The same kind of criticism is inherent in the exclusion of any kind of visual memory from Claude Lantzmann's film Shoah.

Recent publications within Holocaust studies have highlighted the problematic aspects of imaginative representations of the Holocaust. Ever since Adorno proclaimed that the Holocaust must not be figured in aesthetic discourse because "it is barbaric to continue to write poetry after Auschwitz" (87), discussion has centered on the question of genre, most critics agreeing that only non-fictional ego-documents can appropriately represent the Holocaust. There are technical as well as ethical reasons for this view. Lawrence Langer has argued that Holocaust literature differs from other meta-historical narratives because it does not have the same artistic freedom:

When the Holocaust is the theme, history imposes limitations on the supposed flexibility of artistic license. We are confronted by the perplexing challenge of the reversal of normal creative procedure: instead of Holocaust fictions liberating the facts and expanding the range of their implications. Holocaust facts enclose the fictions, draw the reader into an ever narrower area of association, where history and art stand guard over their respective territories, wary of abuses that either may commit upon the other. (117)

Thus, it is seen as morally reprehensible to alter or manipulate the historical facts, as imaginative discourse is invariably bound to do. On the other hand, Robert Scholes has rightly pointed out that "[a]ll writing, all composition, is construction. We do not imitate the world, we construct versions of it" (7). Historiographic as well as imaginative representations of the Holocaust are therefore necessarily manipulative and reductive. As James Young has argued, even the experience of history is dependent upon cultural and narrative frames. If such frames do not exist, historic events remain inaccessible to experience and hence to representation. Narrative frames or meta-narratives therefore do not distort history but allow it to be experienced and witnessed.

I would like to take up van Alphen's suggestion that it is the lack of conventional narrative frames that makes the Holocaust so difficult to represent. Because there are no conventional narrative frames that fit the Holocaust, survivors were not able to experience the historic events and hence they could not talk about the events later on. This makes the Holocaust an "untellable story": "Untellable stories include those narratives that enfold the inarticulable parts of our lives. Untold or told, these stories seem to lack stability, coherency and sense in the ways we customarily evaluate stories and narratives" (Hyland-Russell 100). Van Alphen discusses a number of media and genres, both imaginative and documentary (historical autobiography, Holocaust testimonies, movies, and art installations) and comes to the conclusion that imaginative discourse is most suited to representing the Holocaust, because unlike documentary evidence, which can never show the horror of the Holocaust in its all-encompassing reality, imaginative discourse is able to create "Holocaust effects." "When I use the term Holocaust effect," van 
Alphen explains,

I do so to emphasize a contrast with the term Holocaust representation. A representation is by definition mediated. It is an objectified account. The Holocaust is made present in the representation of it by means of reference to it. When I call something a Holocaust effect, I mean to say that we are not confronted with a representation of the Holocaust, but that we, as viewers or readers, experience directly a certain aspect of the Holocaust or of Nazism .... In such moments the Holocaust is not re-presented, but rather presented or re-enacted. (10)

Like the reality effect evoked by photography, the Holocaust effect is a performative rather than a constative act; it does not seek to reproduce the horror of the Holocaust, but provokes a reaction analogous to that experienced by Holocaust victims.

The effect created by The Emigrants is slightly different from van Alphen's Holocaust effect. What is evoked in The Emigrants is not the experience of Holocaust victims, but that of Holocaust survivors. Since the stories describe not the Holocaust itself, but the difficulty of remembering and framing it, The Emigrants creates a meta-poietic discourse. Perched between remembering and forgetting, highlighting the comparative difficulties in verbal and pictorial systems of memory storage, the imagetext of The Emigrants becomes itself a site of remembrance. Memory and remembrance are the topics of the concluding paragraphs of The Emigrants. After his final visit to the sick Max Aurach, the narrator sits alone in his hotel room in Manchester when he is suddenly visited by a set of memories. This sudden and uncontrollable mémoire involontaire has both aural and pictorial aspects. It seems to the narrator that he is hearing a music hall singer from the 1960s, a strange dwarf-like creature by the name of Siegfried (352). This obscure aural presence is accompanied by a set of images that appear on the backdrop of Siegfried's imaginary stage. The narrator then describes these mental images, which turn out to be memories of an exhibition showing photographs taken in 1940 in the ghetto of Lodz or Litzmannstadt (as it was then called).

These documentary photos, which come closer to representing the Holocaust than anything else in The Emigrants, are not reproduced. We only see them with the mental eye of the narrator, framed by the narrator's associations. While the emblematic pictures introducing the first two stories guide the reception process by opening up an associative subspace, the concluding passage demonstrates this evocative power of images through the narrator's deeply personal reaction. Thus, the reader is shown how a successful narrative framing of Holocaust photos might work. In the narrator's memory, the ghetto photographs become laden with symbolic meaning. One photo in particular is singled out in his imagination: the picture of the three carpet weavers. "I consider what the names of these three women may have been," the narrator reflects: "Roza, Luisa and Leah or Nona, Decuma and Morta, daughters of the night, with spindle and yarn and scissors" (355). In the narrative frame provided here, three anonymous women in the Lodz ghetto are transformed into the mythological Fates, staring straight at the spectator and deter- 
mining the length of his life with their scissors. This may seem ironic, since it was the fate of these women which was cruelly determined at the Wannsee conference. But if we read this evocative description together with the emblematic structure introducing The Emigrants, we will understand that the narrator refers to the power the dead hold over us, and the debt we owe them.

\section{Works Cited}

Adorno, Theodor W. "Engagement." Notes to Literature. Trans. Sherry Weber Nicholsen. 2 vols. New York: Columbia University Press, 1992. 2: 776-794.

Bal, Mieke. Double Exposures: The Subject of Cultural Analysis. New York: Routledge, 1996.

-. "Narrative and the Visual and Literary Arts." Aesthetics. Ed. Michael Kelly. Oxford: Oxford University Press, 1998. 328-331.

-. Quoting Caravaggio: Contemporary Art, Preposterous History. Chicago: University of Chicago Press, 1999.

—. Reading "Rembrandt": Beyond the Word-Image Opposition. Cambridge: Cambridge University Press, 1991.

Barthes, Roland. The Rustle of Language. Trans. Richard Howard. New York: Hill and Wang, 1986.

—. Camera Lucida: Reflections on Photography. Trans. Richard Howard. New York: Hill \& Wang, 1981.

Boehm, Gottfried, ed. Was ist ein Bild? München: Fink, 1994.

Bruner, Jerome. “The Autobiographical Process.” Current Sociology 43.2-3 (1995): 161 177.

Burgin, Victor. The End of Art Theory: Criticism and Post-Modernity. Atlantic Highlands: Humanities Press, 1986.

Detering, Heinrich. "Große Literatur für kleine Zeiten. Ein Meisterwerk: W. G. Sebalds Die Ausgewanderten." FAZ 17 Nov. 1992. Rpt. in Far from Home: W. G. Sebald. Ed. Franz Loquai. Bamberg: Fussnoten zur Literatur, 1995. 71-75.

Duras, Marguerite. Practicalities: Marguerite Duras Speaks to Michel Beaujour. Trans. Barbara Bray. New York: Grove Weidenfeld, 1990.

Eakin, Paul John. Fictions in Autobiography: Studies in the Art of Self-Invention. Princeton: Princeton University Press, 1985.

Easton, M. G. Illustrated Bible Dictionary. 3rd ed. New York: Thomas Nelson, 1897.

Freedman, Jill, and Gene Combs. Narrative Therapy: The Social Construction of Preferred Realities. New York: Norton, 1996.

Gilmore, Leigh. Autobiographics: A Feminist Theory of Women's Self-Representation. New York: Cornell University Press, 1994.

Goetschel, Willi. "Zur Sprachlosigkeit von Bildern.” Bilder des Holocaust: LiteraturFilm-Bildende Kunst. Ed. Manuel Köppen and Klaus Scherpe. Köln/Weimar/Wien: Böhlau, 1997. 131-144.

Gusdorf, Georges. "The Conditions and Limits of Autobiography." Autobiography: Essays Theoretical and Critical. Ed. James Olney. Princeton: Princeton University Press, 1980. 28-48.

Hirsch, Marianne. Family Frames: Photography, Narrative and Postmemory. Cambridge: Harvard University Press, 1997.

Holstein, James A., and Jaber F. Gubrium. The Self We Live By: Narrative Identity in a Postmodern World. Oxford: Oxford University Press, 2000. 
Hyland-Russell, Tara Diane. "The Storied Nautilus: Life Writing, Narrative Therapy and Women's Self-Storying.” Diss. University of Calgary, 2001.

Jaubert. Alain. Fotos, die lügen: Politik mit gefälschten Bildern. Trans. Wolfgang Geiger and Silvia Hissen. Frankfurt: Athenäum, 1989.

Jean Paul. "Vorschule der Ästhetik." Werke. Ed. Norbert Miller. Vol.5. München: Hanser, 1960. 6 vols.

Langer, Lawrence L. "Fictional Facts and Factual Fictions." Reflections of the Holocaust in Art and Literature. Ed. Randolph L. Braham. New York: Institute for Holocaust Studies, 1990. 117-130.

Lantzmann, Claude, dir. Shoah. Les Films Aleph and Historia Films, 1985.

Mitchell, W. J. T. Picture Theory: Essays on Verbal and Visual Representation. Chicago: University of Chicago Press, 1994.

Pöppel, Ernst. "Drei Welten des Wissens-Koordinaten einer Wissenswelt." WeltwissenWissenswelt. Ed. Christa Maar et al. Köln: DuMont, 2000. 21-39.

Rorty, Richard. Philosophy and the Mirror of Nature. Princeton: Princeton University Press, 1979.

Schacter, Daniel, and Elaine Scarry, eds. Memory, Brain and Belief. Cambridge: Harvard University Press, 2000.

Scholes, Robert. Structural Fabulation. Notre Dame: University of Notre Dame Press, 1975.

Sebald, W. G. Die Ausgewanderten. Frankfurt: Fischer, 1994.

Tichborne, Chidiock. "Tichborne's Elegy." The Oxford Anthology of English Literature. Ed. Frank Kermode and John Hollander. 2 vols. Oxford: Oxford University Press, 1973. 1: 611.

van Alphen, Ernst. Caught by History. Stanford: Stanford University Press, 1997.

von Braun, Christina. Die schamlose Schönheit des Vergangenen: Zum Verhältnis von Geschlecht und Geschichte. Frankfurt: Neue Kritik, 1989.

White, Michael, and David Epston. Narrative Means to Therapeutic Ends. New York: Norton, 1990.

Young, James. Writing and Rewriting the Holocaust: Narrative and the Consequences of Interpretation. Bloomington: Indiana University Press, 1990. 